\title{
INFLUÊNCIA DO PREPARO DO SOLO E DA NATUREZA DO FERTILIZANTE NITROGENADO NA CULTURA DO MILHO ${ }^{1}$
}

\author{
J.L. FAVARIP \& A.L. FANCBU. ${ }^{3}$
}

RESUMO: Foi instalado um ensaio de campo, em solo Podz6lico Vermelho-Escuro latossolico (PELa), para avaliar a influência do preparo do solo e a natureza da fonte do fertilizante nitrogenado, para adubackio em cobertura, na cultura do milho. Os tipos de preparo do solo avaliados foram o convencional e o plantio direto. Em relaģ̄o as fontes de nitrogenio, foram utilizadas: uma s6lida, o sulfato de amónio (20\%N), e outra fluida, - uran (32\%N), aplicados à superfície do solo sem incorporação. A absorção de nitrogênio (mg/planta) foi determinada nas folhas, colmos, panículas e espigas, aos 53 e 67 dias ap6s a emergencia das plantulas. Na colheita, ap6s a maturidade fisiologica, foi determinada a quantidade de nitrogênio acumuladoe exportado, bem como a produçăo de grăos e alguns de seus componentes. $O$ tipo de preparo do solo não apresentou influência na produçăo no primeiro ano de sua implantação. Entretanto, o plantio direto permitiu o aproveitamento do nitrogênio, mesmo quando se verificou reduçāo na disponibilidade da água, estimada, através do balanço hidrico. Deseritores: milho, preparo do solo, fertilizante nitrogenado.

\section{INFLUENCE OF SOIL TILLAGE AND SOURCE OF NITROGEN FERTILIZER ON CORN PRODUCTTVTYY.}

SUMMARY: The effect of soil tillage and source of nitrogen fertilizer applied as sidedressing on corn was studied by means of a field trial conducted on a latosolic Darkred Podzolic soil (PELa). Soil tillage treatments were conventional and notillage soil seed-bed preparation. Nitrogen sources were ammonium sulfate (solid, 20\%N) and uran (liquid, $32 \% \mathrm{~N}$ ), sidedressed 40 days after sedling emergence. Nitrogen uptake by the plants was evaluated by determining $N$ content in leaves, stalks, panicles and ear, 53 and 67 days after seedling emergence (13 and 27 days after sidedressing). Harvest was done after physiological maturity was reached by the corn crop. Treatment effects on corn production were determined through yield parameters such as ear lenght and diameter, grain and ear weight and a ratio between these two. Analysis and interpretation of the results indicated that soil treatment had no effect on corn yield in the first cropping year. The results showed, however, a higher nitrogen uptake by the corn plants in the no-tillage and liquid nitrogen (uran) tretments which could be atributed to a rainfall defficiency prevailing in the period when the plants were sampled for analysis (53 and 67 days after plant emergence).

Key Words: maize, soil tillage, nitrogen fertilizer.

\section{INTRODUÇÃO}

É polêmico o comportamento do nitrogênio, no plantio direto, pois,as condições proporcionadas influenciam diretamente os principais fatores relacionados à sua eficiência, tais como: a imobilização biológica (DORAN, 1980 e TOUCHTON \&
HARGROVE, 1982), volatilização (VOLK, 1959; MEYER et al., 1961; FENN \& MIYAMOTO, 1981 e BOUWMEESTER et al., 1985), lixiviação e mineralização (THOMAS et al., 1973; PHILLIPS \& YOUNG, 1973 e McMAHON \& THOMAS, 1976).

A necessidade de nitrogênio no plantio direto é superior aquela observada no plantio convencional

${ }^{1}$ Pesquisa realizada pelo primeiro autor como parte dos requisitos para obtenção do título de Mestre em Fitotecnia.

${ }^{2}$ Engenheiro Agrônomo, Técnico de Nivel Superior do Departamento de Agricultura da ESALQ/USP - CEP 13418-900-PIRACICABA-SP.

${ }^{3}$ Engenheiro Agronomo, Professor Doutor do Departamento de Agricultura da ESALQ/USP, CEP 13418-900PIRACICABA-SP. 
(PHILLIPS \& YOUNG, 1973 e THOMAS et al., 1973). Entretanto, LAL (1974) afirmou que esta constatação se verifica durante a fase inicial de implantação do plantio direto.

Com relação à concentração foliar de nitrogênio, fósforo e potássio, MOODY et al., (1961), não constataram diferenças significativas ao nível de 1\%. Entretanto, para LAL (1979) e MUZILLI (1983) a concentração de nitrogênio nas plantas desenvolvidas neste sistema foi geralmente inferior aquela observada no plantio convencional.

A precipitação pluvial e a irrigação podem constituir em importantes mecanismos para diminuir as perdas de nitrogênio amoniacal, pela volatilização, ainda que a úreia ou os fertilizantes com nitrogênio amídico sejam aplicados superficialmente (FENN \& MIYAMOTO, 1981 e BOUWMEESTER et al., 1985).

KIEHL (1989) observou difusão descendente de nitrogênio amoniacal, resultante da hidrólise enzimática da úreia aplicada na supercifie do solo.

LAL (1979) relata a existência de duas correntes de pensamento sobre o assunto. Uma postula que a eficiencia dos fertilizantes é maior nos sistemas sem revolvimento do solo enquanto a outra apresenta argumentações contrárias.

Do exposto parece oportuno ampliar as pesquisas envolvendo diferentes tipos de preparo do solo e o aproveitamento do fertilizante nitrogenado.

\section{MATERIAL E METODOS}

O experimento foi instalado em solo Podz6lico Vermelho-Escuro latossólico (PELa), na Fazenda Areão, situada no município de Piracicaba, Estado de São Paulo, em área pertencente à Escola Superior de Agricultura "Luiz de Queiroz", da Universidade de São Paulo.

As características químicas do solo antes e após a correção com 1 tonelada de calcário dolomítico (PRNT $=90 \%$ ) e 1 tonelada de termofosfato magnesiano por hectare, encontram-se no Quadro 1. As quantidades dos materiais e sua escolha visava atender a necessidade da diminuição da acidez com a respectiva elevação dos níveis de cálcio, magnésio e fósforo. Ressalte-se que o termofosfato pode ser aplicado logo após a calagem, sem os riscos de insolubilização do fósforo.

O delineamento experimental adotado foi o de blocos casualizados, com parcelas subdivididas, utilizando quatro repetições.

Os tratamentos estudados foram eleitos através da combinação entre os tipos de preparo de solo (plantio convencional e direto) e as duas fontes de fertilizantes nitrogenados (natureza sólida ou sulfato de amônio e natureza fluida ou uran), assim:

(1) Plantio convencional e fonte s6lida (PCFS);

(2) Plantio convencional e fonte fluida (PCFF);

(3) Plantio direto e fonte sólida (PDFS);

(4) Plantio direto e fonte fluida (PDFF).

O preparo convencional do solo foi realizado com uma aração $30 \mathrm{~cm}$ de profundida-de e duas gradeações. No plantio direto, promoveu-se a dessecação das plantas daninhas com glifosate utilizando 2880 gramas do ingrediente ativo/ha, e posteriormente, procedeu-se ao corte da palhada e à abertura do sulco realizado durante a semeadura.

A semeadura do milho hídrido duplo "C525", foi realizada em sulcos de $15 \mathrm{~cm}$ de profundidade espaçados de $0,90 \mathrm{~m}$, através de semeadeira Turba Max, em 10/01/87. A quantidade de fertilizantes foi de $400 \mathrm{Kg} / \mathrm{ha}$ de 4:14:8 (16Kg N, 56 Kg P205, $32 \mathrm{Kg} \mathrm{K20}$ e $32 \mathrm{Kg}$ de $\mathrm{S} / \mathrm{ha}$ )

A adubação nitrogenada por cobertura foi realizada 40 dias após a emergência das plântulas, utilizando uma fonte s6́lida (FS) ou sulfato de amônio $(20 \% \mathrm{~N})$ e uma fonte fluida ou uran $(32 \% \mathrm{~N})$, fornecendo $70 \mathrm{Kg}$ de $\mathrm{N} / \mathrm{ha}$. O nitrogennio contido no uran apresenta a seguinte composição: $14 \%$ de $\mathrm{N}$ amídico, $9 \%$ de $\mathrm{N}$-nítrico e $9 \%$ de $\mathrm{N}$-amoniacal; enquanto que o sulfato de amônio apresenta apenas $\mathbf{N}$ amoniacal.

As amostragens das plantas para a determinação de nitrogênio foram realizadas aos 53, 67 e 138 dias após a emergência das plântulas. Foram coletadas 12 plantas por tratamento e individualizadas em suas partes: folhas, colmo, panícula e espigas, as quais receberam o tratamento requerido para análises dessa natureza, segundo SARRUGE \& HAAG (1974).

$\mathrm{Na}$ maturidade fisiologica, aos 138 dias após a emergência das plântulas, foi realizada a colheita das espigas, e determinada a produção e alguns de seus componentes como os comprimentos e diâmetros médios das espigas e o rendimento de grãos.

\section{RESULTADOS E DISCUSSÃo}

Os resultados da produção de grãos e de alguns de seus compomentes, tais como o comprimento e diâmetro de espigas, peso de espigas e rendimento de grãos estão apresentados nas Tabelas 1,2 e 3 , respectivamente.

Tais resultados revelam que, embora não sejam estatisticamente diferentes, há tendência de superioridade, de forma geral, do plantio convencional 
Quadro 1 - Resultados da análise química do solo da área experimental antes e depois da correção implementada*.

\begin{tabular}{|c|c|c|c|c|c|c|c|c|c|c|c|}
\hline \multirow[t]{2}{*}{ Situação } & \multirow{2}{*}{$\begin{array}{l}\text { Prof. } \\
\text { (cm) }\end{array}$} & \multirow{2}{*}{$\begin{array}{c}{ }^{\text {Pres }} \\
\left.\text { (ug/ } / \mathrm{cm}^{3}\right)\end{array}$} & \multirow{2}{*}{$\begin{array}{c}\text { MO } \\
\%\end{array}$} & \multirow{2}{*}{$\begin{array}{c}\mathrm{pH} \\
\mathrm{CaCl}_{2}\end{array}$} & \multicolumn{6}{|c|}{$\mathrm{meq} / 100 \mathrm{~cm}^{3}$} & \multirow[t]{2}{*}{ V \% } \\
\hline & & & & & $\mathbf{K}$ & $\mathrm{Ca}$ & $\mathbf{M g}$ & $(\mathrm{H}+\mathrm{Al})$ & $\mathbf{s}$ & $\mathbf{T}$ & \\
\hline \multirow{3}{*}{ Antes } & $0-15$ & 8,0 & 2,4 & 4,9 & 0,30 & 0,82 & 0,24 & 3,31 & 1,36 & 4,67 & 29,1 \\
\hline & $15-30$ & 4,0 & 2,2 & 4,9 & 0,14 & 0,53 & 0,34 & 3,08 & 1,01 & 4,09 & 24,7 \\
\hline & $30-50$ & 3,0 & 1,3 & 4,7 & 0,12 & 0,51 & 0,43 & 3,55 & 1,06 & 4,61 & 23,0 \\
\hline & $0-20$ & 29,0 & 2,7 & 5,9 & 0,19 & 4,65 & 1,91 & 2,69 & 6,75 & 9,44 & 71,5 \\
\hline Depois & $20-50$ & 14,0 & 2,6 & 5,4 & 0,09 & 2,62 & 1,21 & 2,95 & 3,95 & 6,90 & 57,2 \\
\hline
\end{tabular}

* Departamento de Química - Setor Nutrição Mineral de Plantas, ESALQ/USP.

sobre o plantio direto e do fertilizante de natureza sólida sobre o fertilizante de natureza fluida em todos os parâmetros avaliados. Em relação a produção de grãos (Tabela 1) esta superioridade chegou ao redor de 9\% quando comparado o tratamento (PCFS) com o tratamento (PDFF), sendo este tratamento inferior aos demais, inclusive para os parâmetros comprimento e diâmetro de espiga, peso da espiga e peso de grãos. Quantitativamente esta superioridade significa aproximadamente $676 \mathrm{Kg}$ de milho por hectare.

Tabela 1 - Dados médios da produção de grãos por parcela $(\mathrm{kg})$ e o equivalente em hectare (kg/ha).

\begin{tabular}{|c|c|c|c|c|}
\hline \multirow{3}{*}{$\begin{array}{l}\text { Tipo de } \\
\text { preparo } \\
\text { do solo } \\
\text { (TP) }\end{array}$} & \multicolumn{4}{|c|}{ Natureza do Fertilizante (NF) } \\
\hline & \multicolumn{2}{|c|}{ S6lido(FS) } & \multicolumn{2}{|c|}{ Fluido (FF) } \\
\hline & $\begin{array}{c}\mathbf{k g} / \\
\text { parcela }\end{array}$ & $\begin{array}{l}\mathrm{kg} / \\
\mathrm{ha}\end{array}$ & $\begin{array}{c}\mathbf{k g} / \\
\text { parcela }\end{array}$ & $\begin{array}{l}\text { kg/ } \\
\text { ha }\end{array}$ \\
\hline \multirow{2}{*}{$\begin{array}{l}\text { Conven } \\
\text { cional } \\
\text { (PC) } \\
\text { Direto } \\
\text { (PD) }\end{array}$} & 9,01 & 8,343 & 8,86 & 8.204 \\
\hline & 8,90 & 8,241 & 8,28 & 7,667 \\
\hline \multicolumn{4}{|c|}{$F=$ Tipo de preparo do solo $(\mathrm{TP})$} & $0,57 *$ \\
\hline \multicolumn{4}{|c|}{$F=$ Natureza do fertilizante (NF) } & $0,71^{*}$ \\
\hline \multicolumn{4}{|c|}{$F=T P \times N F$} & $0,26 *$ \\
\hline
\end{tabular}

ns $=$ não significativo pelo Teste $\mathrm{F}$, ao nível de $5 \%$.
Esta diferença na produção de grãos pode ser atribuida, em parte, tanto à redução no comprimento das espigas $(4,5 \%)$ quanto ao menor diâmetro $(2,3 \%)$, quando analisados os mesmos tratamentos (PCFS) e (PDFF). Para os demais tratamentos (PCFF) e (PDFS) as diferenças em relação ao tratamento (PCFS) são menores. O tamanho e o diâmetro das espigas influenciam, diretamente, seu número de grãos. Assim, possivelmente, reduções nestes parâmetros significam em última análise, redução na produção de grãos, como foi observado no presente trabalho e tamberm por FANCELLI (1988).

A tendência de superioridade do plantio convencional na produção de grãos de milho, observada neste trabalho, ratifica os resultados obtidos por MOODY et al., (1961) e JONES JUNIOR et al., (1969). Também, para JONES JUNIOR et al., (1969), a maior produção de grãos no plantio convencional ocorre apenas no primeiro ano de adoção deste sistema de produção.

As condições climáticas, em relação à precipitação pluvial, insolação e balanço hídrico, constatados nas Figuras 1 e 2, respectivamente, não prejudicaram o florescimento, a polinização e posteriormente a granação, garantindo assim os processos fisiológicos ligados diretamente à produção.

Não foram verificadas também chuvas excessivas (Figura 1) durante 0 pendoamento $e$ polinização, fato que poderia prejudicar o processo produtivo devido à lavagem dos grãos de pólen, proporcionando falhas na granação das espigas. Além disso, nos dias que se sucederam o pendoamento e a polinização, predominaram dias ensolarados, com mais de 8 horas diárias de insolação, de maneira que a taxa fotossintética deve ter permanecido elevada, 
possibilitando condição favorável para a granação e enchimento das espigas conforme observado na Figura 1.

Tabela 2 - Dados médios de comprimento e diâmetro de espigas (cm).

\begin{tabular}{|c|c|c|c|c|c|}
\hline \multirow{3}{*}{$\begin{array}{l}\text { Tipo de } \\
\text { preparo } \\
\text { do solo } \\
\text { (TP) }\end{array}$} & \multicolumn{5}{|c|}{ Natureza do Fertilizante (NF) } \\
\hline & \multicolumn{2}{|c|}{ Sólido(FS) } & \multicolumn{3}{|c|}{ Fluído (FF) } \\
\hline & $\begin{array}{c}\mathbf{k g} \mathbf{l} \\
\text { parcela }\end{array}$ & $\begin{array}{l}\mathrm{kg} / \\
\mathrm{ha}\end{array}$ & $\begin{array}{r}\mathbf{k g} / \\
\text { parce }\end{array}$ & & $\begin{array}{l}\mathrm{kg} / \\
\text { ha }\end{array}$ \\
\hline \multirow{2}{*}{$\begin{array}{l}\text { Conven- } \\
\text { cional } \\
\text { (PC) } \\
\text { Direto } \\
\text { (PD) }\end{array}$} & 17,38 & 4,42 & 17,08 & & 4,44 \\
\hline & 16,72 & 4,41 & 16,63 & & 4,32 \\
\hline & & \multicolumn{2}{|c|}{ Comprimento } & Dis & metro \\
\hline \multicolumn{2}{|c|}{$\begin{array}{l}F=\text { Tipo de preparo } \\
\text { do solo (TP) }\end{array}$} & \multicolumn{2}{|c|}{$3,60 \mathrm{~ns}$} & \multicolumn{2}{|c|}{$1,33 \mathrm{~ns}$} \\
\hline \multicolumn{2}{|c|}{$\begin{array}{l}F=\text { Natureza do } \\
\text { fertilizante (NF) }\end{array}$} & \multicolumn{2}{|c|}{$0,43 \mathrm{~ns}$} & \multicolumn{2}{|c|}{$0,40 \mathrm{~ns}$} \\
\hline \multicolumn{2}{|c|}{$F=T P \times N F$} & \multicolumn{2}{|c|}{$0,13 \mathrm{~ns}$} & \multicolumn{2}{|c|}{$0.72 \mathrm{~ns}$} \\
\hline
\end{tabular}

ns = não significativo pelo Teste $F$, ao nível de $5 \%$.

Devido à execelente condição climática que prevaleceu durante a condução do experimento, era esperado desempenho semelhante da cultura do milho nos dois tipos de preparo do solo, fato tamberm observado por WILHELM (1987).

Os dados analíticos do teor potencial e a quantidade de nitrogênio acumulado (mg/planta), nas diferentes partes da planta até 53 dias após a emergência das plântulas (13 dias após a adubação de cobertura), encontram-se na Tabela 4.

0 intervalo de 13 dias após a adubação de cobertura é suficiente para garantir que parte do nitrogênio absorvido pelas planta, seja proveniente do fertilizante fornecido (ULLOA et al., 1982). Portanto, - comportamento semelhante entre os tratamentos, revela que tanto o tipo de preparo do solo, quanto a natureza do fertilizante, não influenciaram o seu aproveitamento, contrariando as observações de VOLK (1959), KRESGE \& SATCHELL (1960) e MEYER et al., (1961).
O balanço hídrico (Figura 2) revela que o solo apresentava excedente de água quando foi realizada a adubação de cobertura. Anteriormente à adubação ocorreu, ainda, precipitação pluvial de $55,8 \mathrm{~mm}$ acumulada em 2 dias (Figura 1). Tais condições devem ter contribuido para a rápida incorporação do nitrogênio ao solo, através da infiltração do fertilizante, devido a sua solubilidade conforme observam FENN \& MIYAMOTO (1981) e BOUWMEESTER et al., (1985), reduzindo as perdas por volatilização, ainda que tenham sido aplicados superficialmente, não concordando com as observações de MEYER et al., (1961).

Nas condiçōes do experimento o plantio direto apresentou pouca cobertura vegetal na superfície do solo, representada apenas pelos restos das plantas daninhas dessecadas pelos herbicidas. A cultura precedente à instalação do trabalho, a mucuna preta (Mucuna aterrina (Piper \& Tracy) Holland) é uma leguminosa de rápida decomposição, considerando a relaçāo C/N de 22/1, (KIEHL, 1980). Nestas condições pode-se afirmar que a quantidade de resíduos na superficie do solo não representaram maiores dificuldades para a colocação do fertilizante no sistema de plantio direto, como mencionados por VOLK (1959), MEYER et al., (1961), e THOUCHTON \& HARGROVE (1982).

Finalmente, embora não tenha sido avaliada a atividade de microrgamnismos, 6 admissível afirmar que as situações em ambos os tipos de preparo do solo, a rigor, se equivaleram. Portanto, o sistema de plantio direto não deve ser responsável pela perda de parte do fertilizante devido à maior atividade de microrganismos, como observaram DORAN (1980) e TOUCHTON \& HARGROVE (1982).

Estas condições também contribuiram para o comportamento semelhante entre os tratamentos, mesmo para a situação de preparo do solo tão diferente como ocorre entre o plantio direto e o convencional. Ressaltese, ainda, que foi o primeiro ano da implantação do sistema de plantio direto,e que ambos os tipos de preparo do solo foram devidamente adequados física $e$ quimicamente.

Os dados analíticos de porcentagem e quantidade de nitrogênio acumulado obtidos aos 67 dias após a emergência das plântulas (27 dias após a adubação de cobertura), encontram-se na Tabela 5.

O período correspondente a esta avaliação, entre 53 e 67 dias após a emergência das plântulas, caracterizado por elevada taxa de produção de matèria seca, bem como pela grande absorção de nitrogênio (HANWAY, 1962; ALDRUCH \& LENG, 1972 e ANDRADE, 1975). 


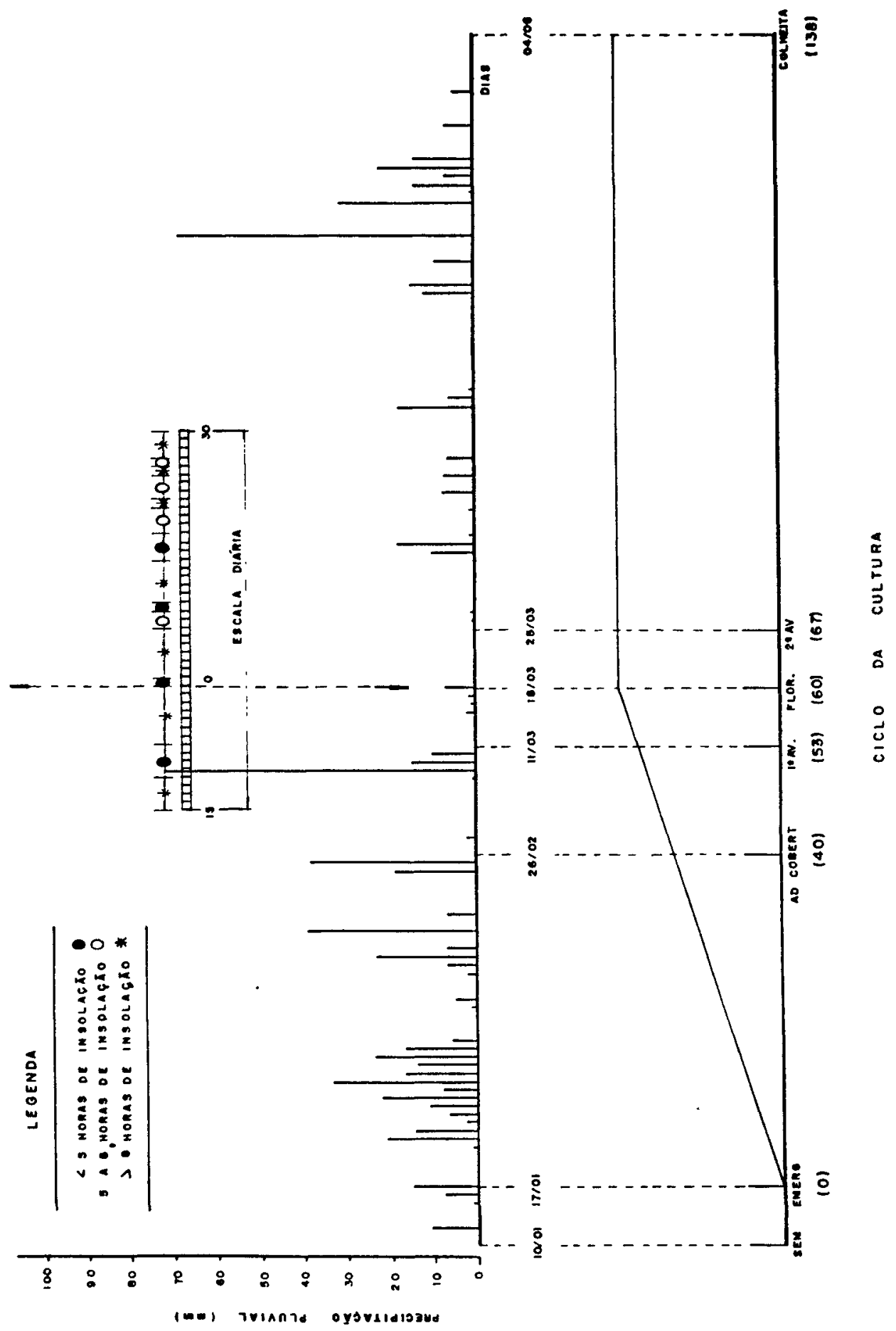

Figura 1 - Distribuição da precipitação pluvial durante o ensaio e a insolação diária durante o florescimento e a granação do milho. 


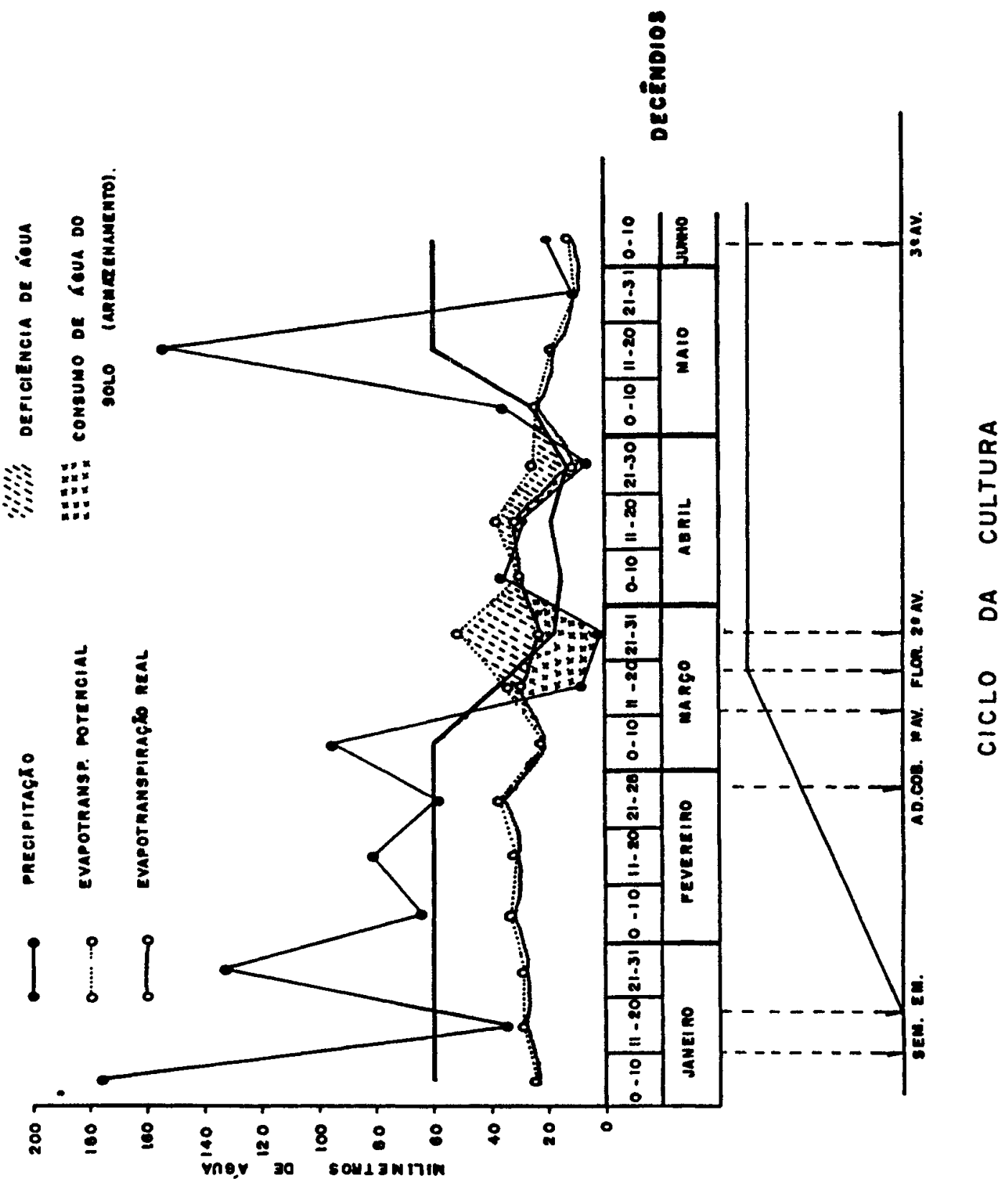

Figura 2 - Balanço hídrico durante o perfodo experimental. Modificado de THORNTHWAITE \& MATHER (1955). Capacidade de água disponível de $60 \mathrm{~mm}$. 
Tabela 3 - Dados médios (kg/parcela) dos pesos de espiga (grãos + sabugo), de grãos e de rendimento de grãos (peso de grãos/peso de espiga).

\begin{tabular}{|c|c|c|c|c|c|c|}
\hline \multirow{3}{*}{$\begin{array}{l}\text { Tipo de } \\
\text { Preparo do } \\
\text { Solo (TP) }\end{array}$} & \multicolumn{6}{|c|}{ NATUREZA DO FERTILIZANTE (NF) } \\
\hline & \multicolumn{3}{|c|}{ SÓLIDO (FS) } & \multicolumn{3}{|c|}{ FLUÍDO (FF) } \\
\hline & peso espiga & peso grãos & rend. grãos & peso espiga & peso grãos & rend. grãos \\
\hline \multirow{3}{*}{$\begin{array}{l}\text { Convencio- } \\
\text { nal (PC) } \\
\text { Direto (PD) }\end{array}$} & 10.55 & 9,01 & 0,85 & 10,34 & 8,86 & 0,86 \\
\hline & 10,39 & 8,90 & 0,36 & 9,69 & 8,28 & 0,85 \\
\hline & & & & $\begin{array}{l}\text { peso de } \\
\text { espiga }\end{array}$ & $\begin{array}{l}\text { peso de } \\
\text { grãos }\end{array}$ & $\begin{array}{l}\text { rendimento } \\
\text { de grãos }\end{array}$ \\
\hline \multirow{2}{*}{\multicolumn{4}{|c|}{$\begin{array}{l}F=\text { tipo de preparo do solo }(\mathrm{TP}) \\
F=\text { Natureza do Fertilizante }(\mathrm{NF})\end{array}$}} & $0.66 \mathrm{~ns}$ & $0,57 \mathrm{~ns}$ & $0,04 \mathrm{~ns}$ \\
\hline & & & & $0,83 \mathrm{~ns}$ & $0,71 \mathrm{~ns}$ & $0,004 \mathrm{~ns}$ \\
\hline \multicolumn{4}{|c|}{$\mathbf{F}=\mathbf{T P} \times \mathbf{N F}$} & $0,35 \mathrm{~ns}$ & $0,26 \mathrm{~ns}$ & $0,40 \mathrm{~ns}$ \\
\hline
\end{tabular}

ns $=$ não significativo pelo teste $F$, ao nível de $5 \%$.

Tabela 4 - Porcentagem média de nitrogênio e quantidade de nitrogênio ( $\mathrm{mg} /$ planta) contido nas diferentes partes da planta 53 dias após a emergência das plântulas (13 dias após aduba nitrogenada de cobertura).

\begin{tabular}{|c|c|c|c|c|c|c|c|c|c|c|c|c|}
\hline \multirow{4}{*}{$\begin{array}{l}\text { Tipo de } \\
\text { preparo } \\
\text { do solo } \\
\text { (TP) }\end{array}$} & \multicolumn{12}{|c|}{ Natureza do Fertilizante (NF) } \\
\hline & \multicolumn{6}{|c|}{ Sólido (FS) } & \multicolumn{6}{|c|}{ Fluído (FF) } \\
\hline & \multicolumn{2}{|c|}{ Folha } & \multicolumn{2}{|c|}{ Colmo } & \multicolumn{2}{|c|}{ Panícula } & \multicolumn{2}{|c|}{ Folha } & \multicolumn{2}{|c|}{ Colmo } & \multicolumn{2}{|c|}{ Panícula } \\
\hline & $\%$ & $\mathrm{mg}$ & $\%$ & mg & $\%$ & $\mathrm{mg}$ & $\%$ & $\mathrm{mg}$ & $\%$ & $\mathrm{mg}$ & $\%$ & mg \\
\hline $\begin{array}{l}\text { Conven } \\
\text { cional } \\
\text { (PC) }\end{array}$ & 2.64 & 1037 & 1.34 & 1211 & 2.63 & 115 & 2.48 & 1103 & 1.19 & 1004 & 2.41 & 117 \\
\hline \multirow[t]{2}{*}{$\begin{array}{l}\text { Direto } \\
\text { (PD) }\end{array}$} & 2.77 & 1083 & 1.28 & 1078 & 2.51 & 102 & 2.47 & 1068 & 1.15 & 940 & 2.71 & 133 \\
\hline & & & \multicolumn{3}{|c|}{ Folha } & \multicolumn{3}{|c|}{ Colmo } & \multicolumn{4}{|c|}{ Panícula } \\
\hline \multicolumn{3}{|c|}{$\begin{array}{l}\text { F - Tipo de preparo do solo } \\
\text { (TP) }\end{array}$} & \multicolumn{3}{|c|}{$0.01 \mathrm{~ns}$} & \multicolumn{3}{|c|}{$1.56 \mathrm{~ns}$} & \multicolumn{4}{|c|}{$0.01 \mathrm{~ns}$} \\
\hline \multicolumn{3}{|c|}{$\begin{array}{l}\text { F - Natureza do Fertilizante } \\
\text { (NF) }\end{array}$} & \multicolumn{3}{|c|}{$0.24 \mathrm{~ns}$} & \multicolumn{3}{|c|}{$4.81 \mathrm{~ns}$} & \multicolumn{4}{|c|}{$0.44 \mathrm{~ns}$} \\
\hline \multicolumn{3}{|c|}{ F - TP $\times$ NF } & \multicolumn{3}{|c|}{$0.60 \mathrm{~ns}$} & \multicolumn{3}{|c|}{0,19 ns } & \multicolumn{4}{|c|}{$0,34 n s$} \\
\hline
\end{tabular}

ns = não significativo pelo teste $\mathrm{F}$, ao nível de $5 \%$ 
Tabela 5 - Porcentagem média de nitrogênio e quantidade de nitrogênio ( $\mathrm{mg} /$ planta) nas diferentes partes da planta, 67 dias após a emergência das plântulas (27 dias após a adubação nitrogenada de cobertura).

\begin{tabular}{|c|c|c|c|c|c|c|c|c|}
\hline \multirow{4}{*}{$\begin{array}{l}\text { Tipo de } \\
\text { Preparo } \\
\text { do Solo }\end{array}$} & \multicolumn{8}{|c|}{ NATUREZA DO FERTILIZANTE (NF) } \\
\hline & \multicolumn{8}{|c|}{ SÓLIDO (FS) } \\
\hline & \multicolumn{2}{|c|}{ Folha } & \multicolumn{2}{|c|}{ Colmo } & \multicolumn{2}{|c|}{ Panícula } & \multicolumn{2}{|c|}{ Espiga } \\
\hline & $\%$ & $\mathrm{mg}$ & $\%$ & mg & $\%$ & mg & $\%$ & mg \\
\hline $\begin{array}{l}\text { Plantio Con- } \\
\text { vencional } \\
\text { (PC) }\end{array}$ & 2.49 & 1002 & 0.92 & 897 & 1.47 & 72 & 1.89 & 882 \\
\hline $\begin{array}{l}\text { Plantio } \\
\text { Direto (PD) }\end{array}$ & 2.91 & 1230 & 0.96 & 920 & 1.52 & 84 & 1.65 & 818 \\
\hline & \multicolumn{8}{|c|}{ FLUf́DO (FF) } \\
\hline $\begin{array}{l}\text { Plantio Con- } \\
\text { vencional } \\
\text { (PC) }\end{array}$ & 2.56 & 1107 & 0.86 & 866 & 1.39 & 72 & 1.70 & 873 \\
\hline \multirow[t]{2}{*}{$\begin{array}{l}\text { Plantio } \\
\text { Direto (PD) }\end{array}$} & 2.57 & 1399 & 1.05 & 1148 & 1.30 & 67 & 1.76 & 1059 \\
\hline & & & & & Folha & Colmo & Panícula & Espiga \\
\hline \multirow{3}{*}{\multicolumn{3}{|c|}{$\begin{array}{l}\text { F - Tipo de preparo do solo (TP) } \\
\text { F - Natureza do Fertilizante (NF) } \\
\text { F - TP x NF }\end{array}$}} & & & $1.95 \mathrm{~ns}$ & $9.06 *$ & $0.17 \mathrm{~ns}$ & $1.22 \mathrm{~ns}$ \\
\hline & & & & & $0.54 \mathrm{~ns}$ & $3.79 \mathrm{~ns}$ & $1.14 \mathrm{~ns}$ & $4.43 \mathrm{~ns}$ \\
\hline & & & & & $0.03 \mathrm{~ns}$ & $6.56^{*}$ & $1.14 \mathrm{~ns}$ & $5.13 *$ \\
\hline
\end{tabular}

ns $=$ não significativo pelo teste $\mathrm{F}$, ao nivel de $5 \%$ de probabilidade

* = Significativo pelo teste $F$, ao nível de $5 \%$ de propabilidade 
Tabela 6 - Peso da matéria seca acumulada pelas diferentes partes da planta até 53 e 67 dias após a emergência das plântulas.

\begin{tabular}{|c|c|c|c|c|c|c|c|c|c|c|}
\hline \multirow{2}{*}{$\begin{array}{l}\text { Dias após } \\
\text { emergência }\end{array}$} & \multirow{2}{*}{$\begin{array}{l}\text { Trata- } \\
\text { mentos }\end{array}$} & \multicolumn{2}{|c|}{ Folha } & \multicolumn{2}{|c|}{ Colmo } & \multicolumn{2}{|c|}{ Panícula } & \multicolumn{2}{|c|}{ Espiga } & \multirow{2}{*}{$\begin{array}{l}\text { Total } \\
\text { Grama }\end{array}$} \\
\hline & & grama & $\%$ & grama & $\%$ & grama & $\%$ & grama & $\%$ & \\
\hline \multirow{4}{*}{$\begin{array}{c}\text { até } \\
53 \text { dias }\end{array}$} & PC e FS & 117.7 & 29.2 & 272.0 & 67.5 & 13.2 & 3.3 & - & - & 402.9 \\
\hline & $P C$ e FF & 133.2 & 33.5 & 252.5 & 63.1 & 14.2 & 3.6 & - & - & 399.9 \\
\hline & $P D$ e FS & 117.9 & 30.9 & 251.7 & 65.9 & 12.2 & 3.2 & - & - & 381.8 \\
\hline & PD e FF & 129.8 & 33.8 & 242.4 & 63.1 & 11.7 & 3.1 & - & - & 383.9 \\
\hline \multirow{4}{*}{$\begin{array}{c}\text { até } \\
67 \text { dias }\end{array}$} & PC e FS & 120.1 & 21.1 & 293.7 & 51.5 & 14.8 & 2.6 & 141.2 & 24.8 & 569.8 \\
\hline & PC e FF & 129.0 & 21.5 & 301.6 & 50.2 & 15.5 & 2.6 & 154.2 & 25.1 & 600.3 \\
\hline & $P D$ e $F S$ & 126.7 & 21.8 & 287.1 & 49.4 & 16.6 & 2.9 & 150.5 & 25.9 & 580.9 \\
\hline & $P D$ e $F F$ & 122.6 & 19.0 & 326.3 & 50.4 & 15.2 & 2.3 & 183.0 & 28.3 & 647.1 \\
\hline
\end{tabular}

PC - Plantio Convencional

PD - Plantio Direto

FS - Adubo de cobertura de natureza sólida

FF - Adubo de cobertura de natureza fluída

Tabela 7 - Médias de nitrogênio acumulado ( $\mathrm{mg} / \mathrm{planta}$ ) para a interação dupla, em relação as determinações no colmo e espiga, 67 dias após a emergência das plântulas (27 dias após a adubação nitrogenada de cobertura).

\begin{tabular}{|c|c|c|c|c|}
\hline \multirow{3}{*}{$\begin{array}{l}\text { Tipo de Preparo } \\
\text { do Solo (TP) }\end{array}$} & \multicolumn{4}{|c|}{ Natureza do Fertilizante (NF) } \\
\hline & \multicolumn{2}{|c|}{ Sólido (FS) } & \multicolumn{2}{|c|}{ Fluído (FS) } \\
\hline & Colmo & Espiga & Colmo & Espiga \\
\hline Convencional (PC) & $897 \mathrm{aA}$ & $882 \mathrm{aA}$ & $866 \mathrm{bA}$ & $873 \mathrm{bA}$ \\
\hline Direto (PD) & $910 \mathrm{aB}$ & $818 \mathrm{aB}$ & $1148 \mathrm{aA}$ & $1059 \mathrm{aA}$ \\
\hline
\end{tabular}

Médias seguidas de letras minúsculas iguais nas colunas não diferem entre si pelo teste Tukey, ao nivel de $5 \%$ de probabilidade.

Médias seguidas de letras maiúsculas iguais nas linhas não diferem entre si pelo teste Tukey, ao nível de $5 \%$ de probabilidade. 


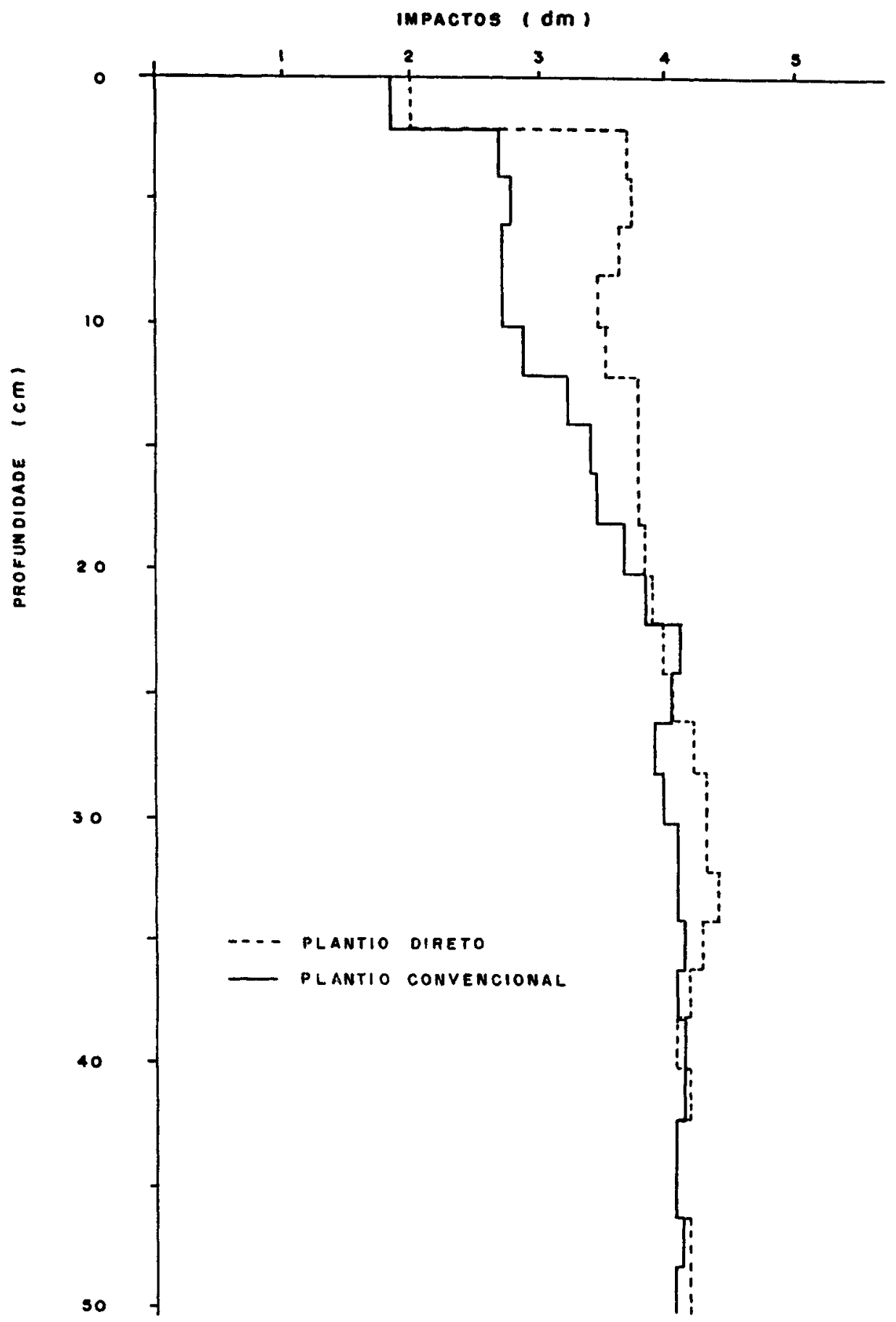

Figura 3 - Resistência à penetração (impactos/dm) com função da profundidade do solo sob preparo convencional e plantio direto. 
Tabela 8 - Dados médios da quantidade de nitrogênio acumulado (mg/planta) e o equivalente em hectare, (kg/ha) nas diferentes partes da planta, na colheita.

\begin{tabular}{|c|c|c|c|c|c|c|c|c|c|c|c|c|}
\hline \multirow{3}{*}{$\begin{array}{l}\text { Trata- } \\
\text { mento }\end{array}$} & \multicolumn{2}{|c|}{ Folha } & \multicolumn{2}{|c|}{ Colmo } & \multicolumn{2}{|c|}{ Panícula } & \multicolumn{2}{|c|}{ Espiga } & \multicolumn{4}{|c|}{ Nitrogênio } \\
\hline & \multirow[t]{2}{*}{$\mathrm{mg}$} & \multirow[t]{2}{*}{$\mathrm{kg} / \mathrm{ha}$} & \multirow[t]{2}{*}{$\mathrm{mg}$} & \multirow[t]{2}{*}{$\mathrm{kg} / \mathrm{ha}$} & \multirow[t]{2}{*}{$\mathrm{mg}$} & \multirow[t]{2}{*}{$\mathrm{kg} / \mathrm{ha}$} & \multirow[t]{2}{*}{$\mathrm{mg}$} & \multirow[t]{2}{*}{$\mathrm{kg} / \mathrm{ha}$} & \multicolumn{2}{|c|}{ extraído } & \multicolumn{2}{|c|}{ exportado } \\
\hline & & & & & & & & & $\mathrm{mg}$ & $\mathrm{kg} / \mathrm{ha}$ & $\mathrm{mg}$ & $\%$ \\
\hline (PC-FS) & 380 & 16.87 & 400 & 17.76 & 60 & 2.66 & 3830 & 170.05 & 4670 & 207.34 & 3830 & 82 \\
\hline (PC-FF) & 390 & 17.32 & 500 & 22.20 & 50 & 2.22 & 3000 & 133.20 & 3940 & 174.94 & 3000 & 76 \\
\hline (PD-FS) & 380 & 16.87 & 410 & 18.20 & 50 & 2.22 & 3500 & 155.40 & 4340 & 192.69 & 3500 & 81 \\
\hline \multirow[t]{2}{*}{ (PD-FF) } & 300 & 13.32 & 340 & 15.10 & 50 & 2.22 & 3030 & 134.53 & 3720 & 165.17 & 3030 & 81 \\
\hline & & & & & \multicolumn{2}{|c|}{ Folha } & \multicolumn{2}{|c|}{ Colmo } & \multicolumn{2}{|c|}{ Panícula } & \multicolumn{2}{|c|}{ Espiga } \\
\hline \multicolumn{5}{|c|}{ F - Tipo de preparo do so } & \multicolumn{2}{|c|}{$0.58 \mathrm{~ns}$} & \multicolumn{2}{|c|}{$0.54 \mathrm{~ns}$} & \multicolumn{2}{|c|}{$0.65 \mathrm{~ns}$} & \multicolumn{2}{|c|}{$0.15 n s$} \\
\hline \multicolumn{5}{|c|}{ F - Natureza do fertilizante (NF) } & \multicolumn{2}{|c|}{$0.95 \mathrm{~ns}$} & \multicolumn{2}{|c|}{$0.03 \mathrm{~ns}$} & \multicolumn{2}{|c|}{$0.49 \mathrm{~ns}$} & \multicolumn{2}{|c|}{$3.13 \mathrm{~ns}$} \\
\hline \multicolumn{4}{|c|}{$F-T P \times N F$} & & \multicolumn{2}{|c|}{$0.69 \mathrm{~ns}$} & \multicolumn{2}{|c|}{$0.68 \mathrm{~ns}$} & \multicolumn{2}{|c|}{$0.31 \mathrm{~ns}$} & \multicolumn{2}{|c|}{$0.24 n s$} \\
\hline
\end{tabular}

ns $=$ não significativo pelo Teste $F$, ao nível de $5 \%$ de probabilidade.

A elevada taxa de crescimento da planta, neste periodo, é devida basicamente ao desenvolvimento do colmo e da espiga (Tabela 6), as quais passaram a ser responsáveis pelo maior acúmulo da matéria seca no período. Portanto, trata-se também de perìodo com elevada demanda por nitrogênio, cuja similaridade com a curva de acúmulo de matéria seca fora constatada por ANDRADE (1975).

Para esta época o plantio direto superou o plantio convencional para todas as partes da planta, embora apenas significamente para o colmo. Em relação à natureza do fertilizante, a fonte fluída superou a fonte sólida, exceto a panícula, conforme mostra a Tabela 5.

A superioridade do plantio direto é comumente observada quando ocorrem condições climáticas desfavoráveis, em relação à precipitação pluvial. A ausência do revolvimento do solo,condiciona a presença de maior microporosidade na sua camada superficial, estimada pela maior resitência à penetração (Figura 3), a qual protegida pela presença de resíduos na superfície, contribui para a conservação de maior teor de água disponível (BLEVINS et al., 1971; LAL, 1975; LOMBARDI NETO et al., 1983 e PHILLIPS \& PHILLIPS, 1984).

O balanço hídrico (Figura 2) revela que houve redução na quantidade de água disponível, no período entre as duas avaliações (53 e 67 dias após a emergência das plântulas), tendo havido apenas $9,3 \mathrm{~mm}$ de precipitação pluvial (Figura 1). Era previsível, portanto, que nestas condições a maior absorção de nitrogênio sob o plantio direto em relação ao convencional.

Foram evidenciadas, ainda, diferenças significativas, ao nível de $5 \%$ de probabilidade para a interação dupla entre tipo de preparo do solo e a natureza da fonte do fertilizante nitrogenado, para as determinações no colmo e espiga cujo teste de Tukey apresentou o resultado constante na Tabela 7. De acordo com os resultados, tal interação deveu-se aos tipos de preparo do solo com o fertilizante de natureza fluida tanto para a determinação no colmo como para a determinação na espiga, 67 dias após a emergência das plântulas. A melhor combinação para ambas as variações foi correspondente ao plantio direto com o fertilizante fluido uran.

Embora o período referente a esta avaliação compreendido entre os dias 53 e 67 após a emergência das plântulas, represente elevada taxa de produção de matéria seca (Tabela 6) é difícil, nesta época, avaliar a participaçào $\mathrm{da}$ fonte do fertilizante no fornecimento do nitrogênio, nas condições do experimento. Isto porque, após o florescimento das plantas, ocorido 60 dias após a emergência, há redistribuição interna de nitrogênio 
dos 6rgãos vegetativos como folhas e colmo para a formação e granação das espigas, não significando, portanto, nitrogênio absorvido diretamente do solo e oriundo, necessariamente, do fertilizante aplicado.

As quantidades de nitrogênio acumuladas (mg/planta) nas diferentes partes da planta, na maturidade fisiológica, ocorrida 138 dias após a emergência das plântulas, encontram-se na Tabela 8.

No presente trabalho, tanto o nitrogênio contido nos grãos, quanto aquele encontrado na palha da espiga de no sabugo foram considerados como exportados pela colheita.

Para esta época, a quantidade de nitrogênio acumulado nas espigas apresentou, em valores absolutos, a seguinte ordem decrescente: (PCFS), (PDFS), (PDFF) e (PCFF), consequentemente, a quantidade de nitrogênio exportado apresentou igual comportamento.

A quantidade de nitogênio acumulado na planta, foi superior àquela obtida por ANDRADE (1975) e semelhante à encontrada por ULLOA et al. (1982). Aproximadamente $80 \%$ de nitrogênio extraído nesta época, foi exportado pelas espigas, superando os valores encontrados pelos mesmos autores.

A produção de grãos obtida para diferentes tratamentos (Tabela 1) e a quantidade de nitrogênio acumulado na planta e exportado (Tabela 8), revelaram que o nitrogênio fornecido pela adubação de cobertura foi suficiente, não tendo limitado o rendimento da cultura. Portanto, nem o tipo de preparo de solo e tampouco, a fonte do fertilizante nitrogenado comprometeram o aproveitamento do nutriente, sugerindo que, para as condições do experimento, não seria necessário aumentar o fornecimento do nutriente. Esta observação não atende as constatações de PHILIPPS \& YOUNG (1973), THOMAS et al., (1973) e McMAHON \& THOMAS (1976), segundo as quais, no sistema de plantio direto, a demanda em nitrogênio, pelas plantas, é aproximadamente 20 a $30 \%$ superior do que aquela exigida no plantio convencional.

Esta observação é reforçada pela análise da Tabela 6, a qual revela que a produção de matéria seca total aos 67 dias após a emergência das plântulas mostrou-se superior no plantio direto.

Era previsível a não existência de diferenças entre o plantio direto e convencional, principalmente porque por ocasião da instalação do experimento foi realizada a efetiva uniformização da área experimental, eliminando-se assim, possíveis entraves de natureza física, mediante a realização da aração profunda $(30 \mathrm{~cm})$ e quimica, com a calagem e fosfatagem corretiva.

Destaque-se ainda tratar-se do primeiro ano de implantação do sistema, e que anteriormente à semeadura do milho havia sido realizada uma adubação verde, com mucuna preta (Mucuna aterrina (Piper \& Tracy) Holland).

As plantas daninhas poderiam também alterar o comportamento da cultura, afetando tanto a produção de grãos quanto os componentes, pela acentuada pressão competitiva que exerceriam notadamente no plantio direto, pois, o seu controle, é baseado no uso de herbicidas, o que nem sempre é eficiente. Entretanto, isto não aonteceu, pois as plantas daninhas foram eficientemente controladas nos dois sistemas de produção.

\section{CONCLUSÕES}

Concluiu-se que o tipo de preparo do solo não apresentou influência na produção da cultura do milho, no primeiro ano de sua implantação. Em condições climáticas adversas, reponsáveis pela redução da água armazenada no solo, o sistema de plantio direto favoreceu o aproveitamento do fertilizante nitrogenado aplicado em cobertura. Nestas condições foi constatada a interdependência dos efeitos entre o mencionado sistema de preparo do solo e a fonte fluida do fertilizante nitrogenado, nas determinações para colmo e espiga.

\section{REFÊRENCIAS BIBLIOGRÁFICAS}

ALDRICH, S.R. \& LENG, E.R. Modern crop production. Cincinnat F \& W Publishing, 1972. $308 \mathrm{p}$.

ANDRADE, A.G. Acumulação diferencial de nutrientes por cinco cultivares de milho (Zea mays L.). Piracicaba, ESALQ/USP. 1975. 91 p. Dissertação de Mestrado.

BLEVINS, R.L.; COOK, D.; PHILLIPS, R.E. Influence of notillage on soil moisture. Agronomy Journal, Madison 63(4): 593-6, 1971.

BOUWMEESTER, R.J.B.; VLEK, P.L.G.; STUMPE, J.M. effect of environmental factors on ammonia volatilization from a Uréa-fertilized soil. Soil Science Society of American Journal. Maison, 49: 376-81, 1985.

DORAN, J.W. Soil microbial and bichemical changes associated whit redutced tillage. Soil Science Society of America Journal. Madison, 44: 76571, 1980. 
FANCELLI, A.L. Influência do desfolhamento no desempenho de plantas e de sementes de milho (Zea mays L.) Piracicaba,SP, ESALQ/USP. 1988. 172 p. Tese de Doutorado.

FENN, L.B. \& MIYAMOTO, S. Ammonia loss and associated reactions of Ureia in Calcareous soil. Soil Science of Society of America Journal, Madison, 45: 537-40, 1981.

HANWAY, J.J. Plant Analysis, guide for com weeds. Better Crops, Atlanta, 46: 50-5, 1962.

JONES JUNIOR, J.N.; MOODY, J.E.; LILLARD, J.H. Effects of tillage, no tillage, and mulch on soil water and plant growth. Agronomy Journal. Madison, 61(5): 719-21, 1969.

KIEHL, J.C. Matéria orgânica e nitrogênio do solo. In: MARCONI A. Curso de atualização em fertilidade do solo. Piracicaba,SP. ESALQ/USP, 1980. p. irreg.

KIEHL, J.c. Distribuição e retenção da amônia no solo após aplicação de Uréia. Revista Brasileira de Ciência do Solo. Campinas, 13: 75-80, 1989.

KRESGE, C.b. \& SATCHELL, D.P. Gaseous loss of ammonia from nitrogen fertilizers applied to soils. Agronomy Journal, Madison, 52(2): 104-7, 1960.

LAL, R. No tillage effects on soil properties and mayze (Zea mays L.) production in Western Nigeria. Plant and Soil. The Hague, 40: 321-31, 1974.

LAL, R. Rate of mulching techniques in tropical soil and water management. Ibadan, IITA. 1975. 38p.

LAL, R. Influence of six years of no tillage and conventional plowing on fertilizer reponse of mayze (Zea mays L.) on an Alfisol in the tropics. Soil Science Society of America Journal, Madison, 43: 399-403, 1979.

LOMBARDI NETO, F.; CASTRO, O.M.; DECHEN, S.C.F.; SILVA, I.R.; BENATTI JUNIOR, R. Sistemas de preparo do solo em relação a erosão e a produção. In: Congresso Brasileiro de Conservação do Solo, 3. Brasília, 1980. Resumos. Campinas, Cargill, 1980. p. 26.
McMAHON, M.A. \& THOMAS, G.W. Anion leaching in two Kentucky under by conventional tillage and a Killed-sod mulch. Agronomy Journal, Madison, 68(3): 437-42, 1976.

MEYER, R.D.; OLSON, R.A.; RHOADES, H.F. Ammonia loses from fertlized Nebraska soils. Agronomy Journal. Madison, 53(4): 241-4, 1961.

MOODY, J.E.; SHEAR, G.M.; JONES JUNIOR, J.N. Growing corn withouth tillage. Notes. Soil Science Society of America Proceedings. Madison, 25(6): 516-7, Nov./Dec. 1961.

MUZILLI, O. Influência do sistema de plantio direto, comparado ao convencional, sobre a fertilidade da camada arável do solo. Revista Brasileira de Ciência do Solo. Campinas, 7:95-102, 1983.

PHILLIPS, R.E. \& S.M. No-tillage agriculture, principles and pratices. New York, Van Nostrand Reinhold, 1984, 306 p.

PHILLPS, S.H. \& YOUNG JUNIOR, H.M. No tillage farming. Milwaukee, Reiman Associates, 1973. 224p.

SARRUGE, J.R. \& HAAG, H.P. Análises químicas em plantas. Piracicaba, ESALQ, 1974, 55p.

SIDIRAS, N.; DERPSCH, R.; MONDARDO, A. Influência de diferentes sistemas de preparo do solo na variação da umidade e rendimento da soja, em Latossolo roxo distrófico (Oxissol). Revista Brasileira de Ciência do Solo, 7: 103-6, 1983.

THOMAS, G.W.; BLEVINS, R.L.; PHILLIPS, R.E. McMAHON, M.A. Effect of a killed sod mulch on nitrate movement and corn yield. Agronomy Journal, Madison, 65(5): 736-9, 1973.

THORNTHWAITE, C.W. \& MATHER, J.R. The water balance. Publications in Climatology, 8(1): 1-104, 1955.

TOUCHTON, J.T. \& HARGROVE, W.L. Nitrogen sources and methods of application for no tillage corn production. Agronomy Journal, Madison, 74(5): 823-926, 1982.

ULLOA, A.M.C.; LIBARDI, P.L.; REICHARDT, K. Utilização do nitrogennio fertilizante por dois 
hibridos de milho. Campinas. Fundação Cargill, 1982, 66p.

VOLK, G.M. Volatile loss of ammonia following surface applications o Urea to Turf or Bare soils. Agronomy Journal, Madison, 51(12): 746-9, 1959.

WILHELM, W.W.;SCHEPERS, J.S.; MILKE. L.N.; DORAN, J.W.; ELLIS, J.R.; STROUP, W.W. Dryland mais development and yield resulting from tillage and nitrogen fertilization pratices. Soil \& Tillage Research, Amsterdam, 10: 167-78, 1987.

Trabalho entregue para publicação em 02.12 .91

Trabalho aprovado para publicação em 10.05 .92 